\title{
Flexural response of multi-stiffened aluminium beams in dock platforms
}

\author{
Rolando Chacón, Enrique Mirambell, Itsaso Arrayago \\ Department of Civil and Environmental Engineering \\ Universitat Politècnica de Catalunya UPC \\ C/Jordi Girona 1-3 Campus Nord UPC. Building C1-207 \\ rolando.chacon@upc.edu
}

\begin{abstract}
In this paper, the flexural response of extruded wrought aluminium girders is presented. This structural element is intended for usage in marine structures such as light docks, marinas and yacht ports. Ease of use, durability, reduced weight, manoeuvrability and the potential development of bespoke sections are appealing properties in such structures that are fulfilled satisfactorily by this type of aluminium elements. Both experimental and numerical analyses are presented. Experimentally, modules of the girders are tested with loading about both minor and major axes. Numerically, the tests are satisfactorily reproduced for the sake of validation and a subsequent exploitation of the model is addressed for further study of the structural response of the girders. A discussion of the results is presented with some design recommendations of these particular structural elements.
\end{abstract}

\section{Introduction}

Extruded wrought aluminium stiffened beams are appealing structural elements with particular interest for marine structures such as marinas, yacht ports and docks due to their reduced weight, durability, corrosion resistance, ease of maintenance and operability with small- to medium crafts. The extrusion process facilitates the design of bespoke cross-sections in which both stiffening and geometrical needs related to operability can be matched in a single element with little- to no need of welding. Research related to the structural response of aluminium elements dates back to 1940 [1] and since then, a considerable amount of experimental and numerical investigations has been published. In particular, for the case of flexural response of I-shaped aluminium beams, several studies related to cross-sectional classification [2], compactness [3-4], local buckling including concentrated loads [5-6] and lateral stability [7] are available. For other types of crosssections such as Channel, Square Hollow and Rectangular Hollow Sections (C, SHS and RHS respectively), the deformation-based design has been proposed [8-10] similarly to other nonlinear metallic materials with pertinent validations using experimental and numerical investigations. Research related to other arbitrary shapes of extruded sections is primarily devoted to the extrusion process and its effect on the final product [11-12]. Durability reports related to inspection, testing and exfoliation of aluminium structural elements are also available [13-14].

Moreover, the structural behaviour of aluminium structural elements has been particularly studied in the marine environment for the case of stiffened plates used as parts of hulls and decks [15-17] in crafts. Durability, corrosion resistance and the ease of weld (using for instance friction stir welding) are appealing properties for the use of such material as part of on- and offshore marine structures. The structural applications in the marine 
environment are thus hulls and decks in high-speed boats, catamarans and superstructures for ships, box-girder bridges in corrosion-prone atmospheres, and walls and floors in offshore modules and containers.

This investigation focuses on the static structural analysis of extruded aluminium beams that are primarily designed as resisting elements in light docks. These structures are presently used along the Spanish littoral in marinas and yacht ports. Considerable aesthetic appeals as well as maintenance, weight and operation advantages provide these elements a promising use as marine light structures. These structures typically include a 3D structural arrangement in which the aforementioned extruded stiffened elements act as longitudinal main girders. On the other hand, transverse and diagonal RHS elements provide an overall structural behaviour. As a result, the design consists of a planar truss whose both lateral chords are the extruded elements whereas diagonal and additional horizontal members act as a platform for the deck. This platform may be built with light materials such as cellular ceramic slim floors, wood, plastic or similar materials. Fig.1(a) displays a general panoramic view of a platform in the Spanish littoral with mooring lines and small- to medium crafts. Fig. 1(b) shows an aluminium platform in a modular form that may be coupled sequentially for different dock lengths of such marinas. Fig. 1(c) displays a real platform in which the truss is highlighted and Fig. 1(d) shows details of the beam with bespoke joints and shapes which are needed in such elements.

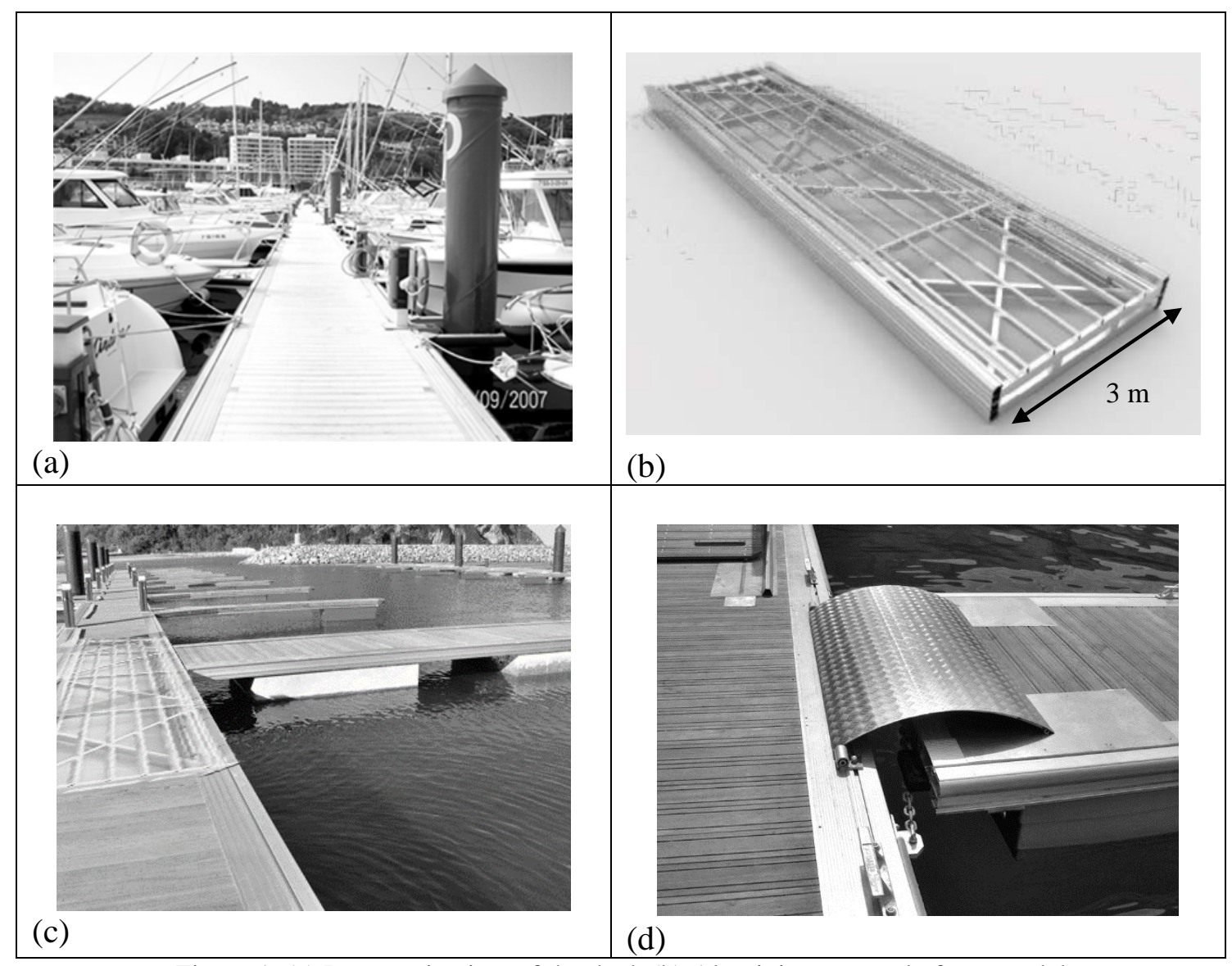

Figure 1. (a) Panoramic view of the dock (b) Aluminium truss platform model

(c) View of the location of the truss in a real platform and (d) Detailing in bespoke sections. [23] 
The flexural response of an extruded multi-panelled, stiffened cellular girder is studied both experimentally and numerically. Section 2 describes a set of tests performed at the Laboratory of Structural Technology of UPC. Two extruded aluminium girders with realistic depth proportions were tested to bending for both major and minor axes. The length of the girder was 4,0 meters in accordance with the laboratory facilities. The former test (bending about minor axis), is related to lateral loads that may be generated by the crafts whereas the latter (bending about major axis) is related to gravity loads acting on the overall structure. Subsequently, section 3 describes a numerical reproduction of such tests for the sake of validating the computational tool used in the study. Thus, numerical vs. experimental comparisons of the results are provided. Finally, section 4 describes a parametric study in which the numerical tool is used systematically in order to evaluate different design situations to which the extruded girder may be subjected to. The characterising methodology shows ultimate loads, failure modes and deformation capacity of the aluminium elements for different situations which gives hints about their flexural response in bending and about their potential weak areas that control these failure modes. It is important to note that other identified potential loading cases such as dynamic impact loading in both wide or concentrated areas are out of the scope of this piece of research.

\section{Experimental investigation}

Two extruded aluminium girders were tested in bending for both minor and major axes under static loads. The tests were performed on elements whose total length was 4,0 meters and varying span for each case. Fig. 2 and Fig. 3 display both the cross-section of the overall truss structure depicted in section 1 respectively. The main girders are the longitudinal elements at each side. Several aspects from these elements are worth pointing out:

- The cross-section of each girder is non-symmetric for minor axis and symmetric for the major axis. From one perspective (minor axis), it may result in a different flexural behaviour for push or pull lateral loads. From the other perspective (major axis), the shear centre does not match with the centroid thus torsional effects may appear. It is worth pointing out that as a whole, the cross-section of the platform including two girders is symmetric.

- The cross-section of the main girders is considerably stiffened. These elements are composed of four closed cells with panels with different plate thicknesses. The thinnest plate is $3 \mathrm{~mm}$ whereas the thickest $16 \mathrm{~mm}$.

- Major axis has a considerably greater inertia than the minor axis.

- Intrados, the main girders allow the assembly of other aluminium elements. Extrados, the indentations of the elements allow operation with mooring lines or similar equipment. 

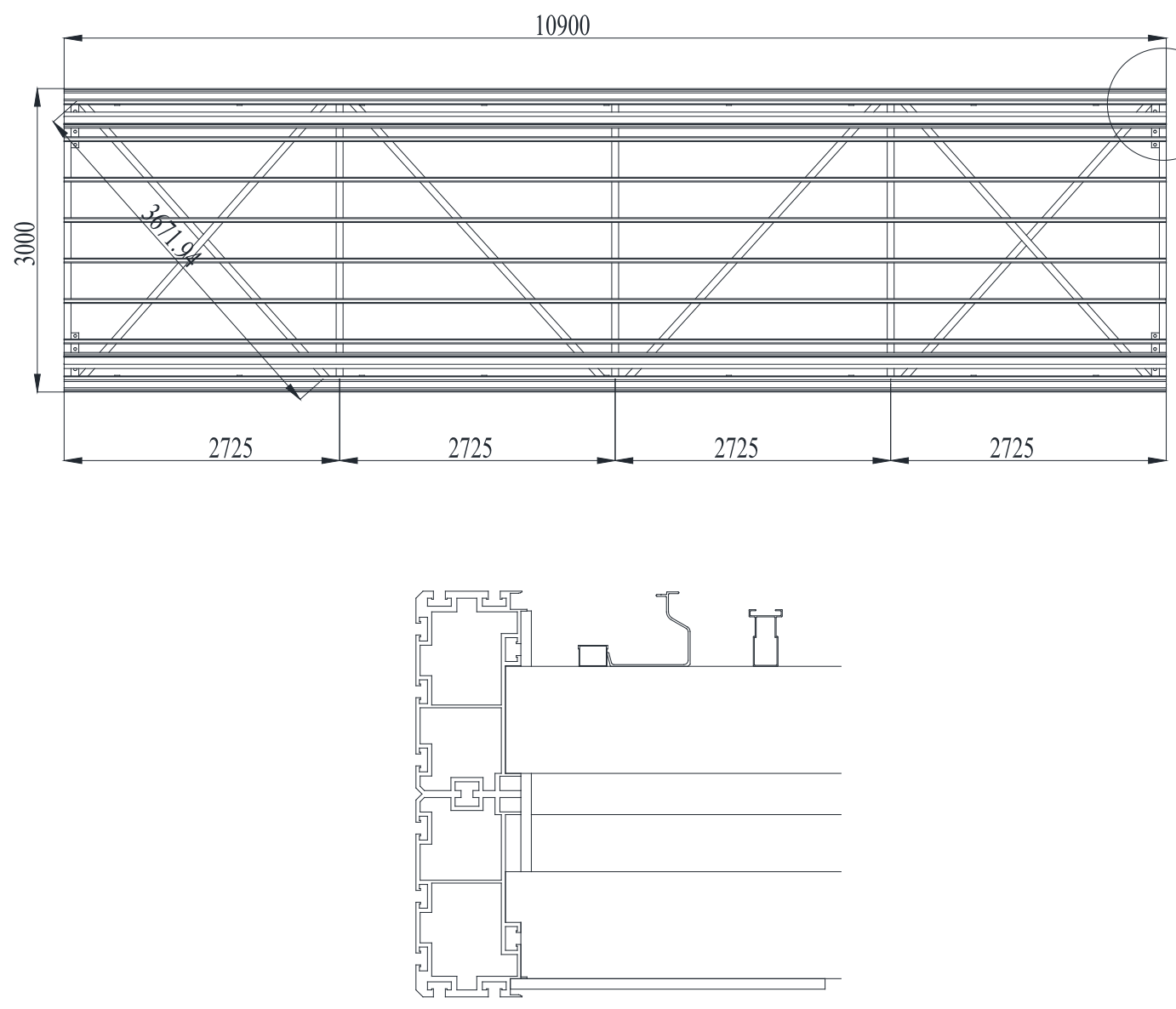

Figure 2. Top view and details of the aluminium truss.

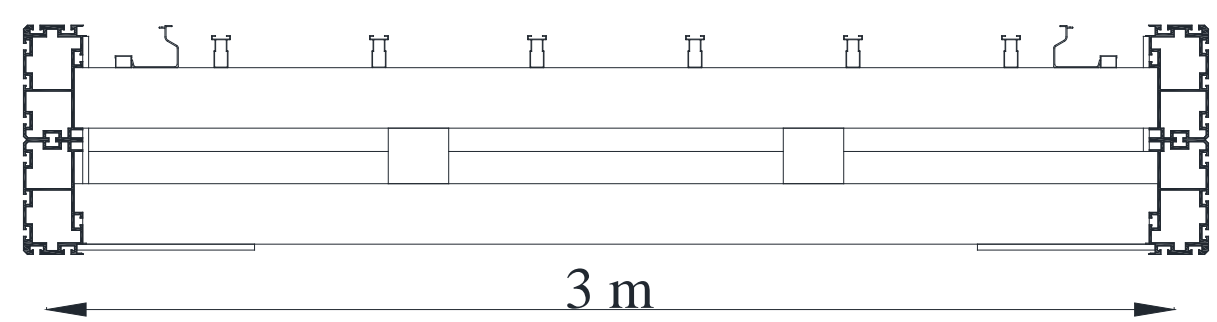

Figure 3. Cross-section of the aluminium truss.

Fig. 4 shows general views of the tests setups for both cases (minor axis Fig. 4(a), major axis Fig. 4(b)). In both cases, the tests were designed as simply supported with a concentrated load at mid-span (3-point bending test). 


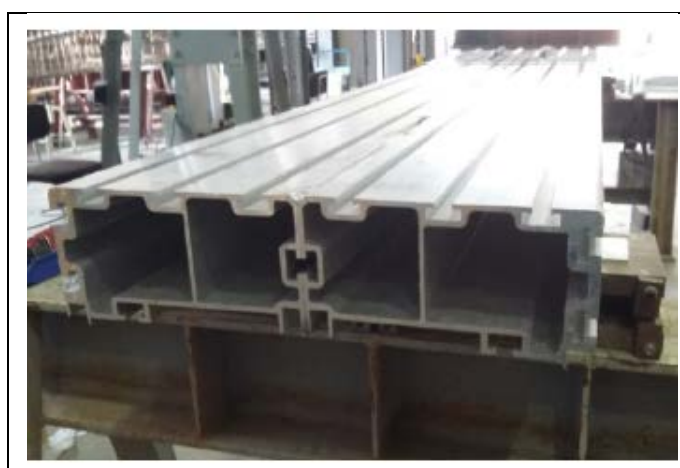

(a)

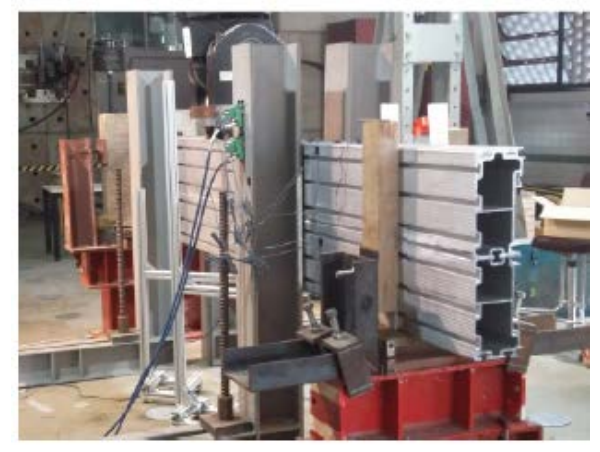

(b)

Figure 4. General view of test setup for minor axis (a) and major axis (b) bending tests.

The tested girders were extruded from a AW 6005A T6 wrought aluminium alloy with a proof stress value $f_{0}=251 \mathrm{~N} / \mathrm{mm}^{2}$ evaluated by means of $0,2 \%$ offset method according to the suppliers with a conventional elastic limit of proportionality $\mathrm{f}_{\mathrm{p}} \approx 150 \mathrm{~N} / \mathrm{mm}^{2}$ and a corresponding value of $\varepsilon_{\mathrm{p}}=0,002$.

\subsection{Results for minor axis bending}

The test for the case of minor axis bending was performed on an aluminium girder with $3100 \mathrm{~mm}$ span. This distance was chosen due to laboratory facilities regarding the vertical stiffening of the girders and the available support hinges. A monotonically increasing load was introduced with a rigid HEB100 steel beam by means of a MTS $1000 \mathrm{kN}$ hydraulic jack under displacement control $(1,0 \mathrm{~mm} / \mathrm{min})$. A neoprene pad was placed under the rigid beam to avoid indentations on the loaded flange. Strain gauges were fastened on top and bottom flanges of the girder (mid-span) whereas the vertical deflection was continuously measured with a Linear Variable Displacement Transducer (LVDT) throughout the test at mid-span section. Fig. 5 displays the structural scheme of the test for this particular case. It is worth noticing that this particular type of loading corresponds to a push lateral load on the extrados of the elements.

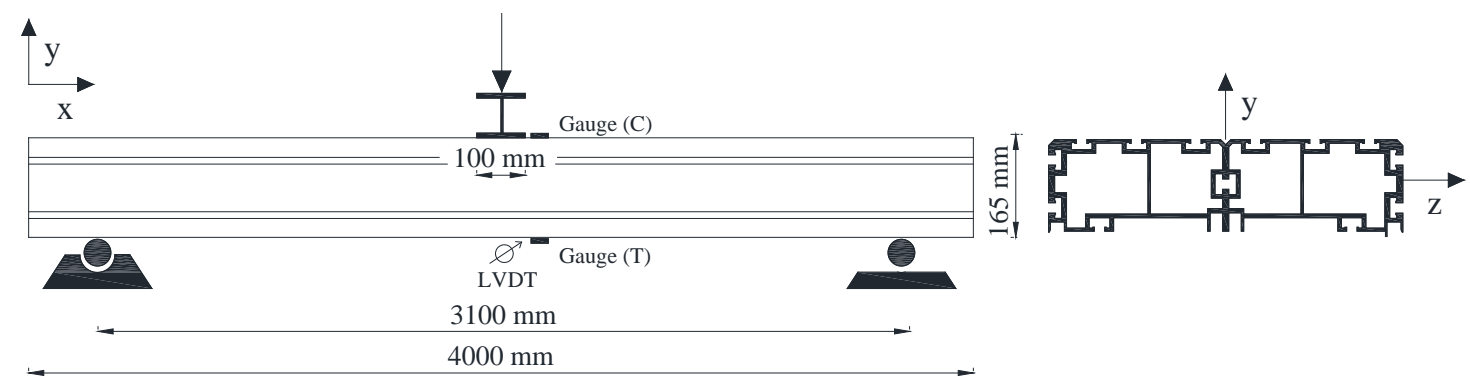

Figure 5. Lateral scheme of minor axis bending test.

The load-displacement plot is displayed in Fig. 6. Fig. 7 shows the load-strain plots for gauges located in tension (T) and compression (C). For minor axis bending, the observed behaviour in the load-displacement plot shows a linear branch up to a value of approximately $200 \mathrm{kN}$. A gradual loss of linearity occurs up to a value of 232,8 kN. In the load-strain plot at initial stages, symmetric slopes are observed (for $\mathrm{T}$ and $\mathrm{C}$ ). Subsequently, the loss of linearity corresponds to the nonlinear stress-strain curve of the material (approximately at $\varepsilon=0,002$, corresponding to the limit of proportionality as expected). The element behaved in a ductile fashion with a considerable deformation capacity at peak load. The test was stopped and the girder was unloaded for a value of 
$200 \mathrm{~mm}$ and the obtained unloading slope was practically parallel to the initial loading slope. Fig. 8 shows an isometric view of the girder before the test and Fig. 9 displays a a similar view of the failure mode at peak load.

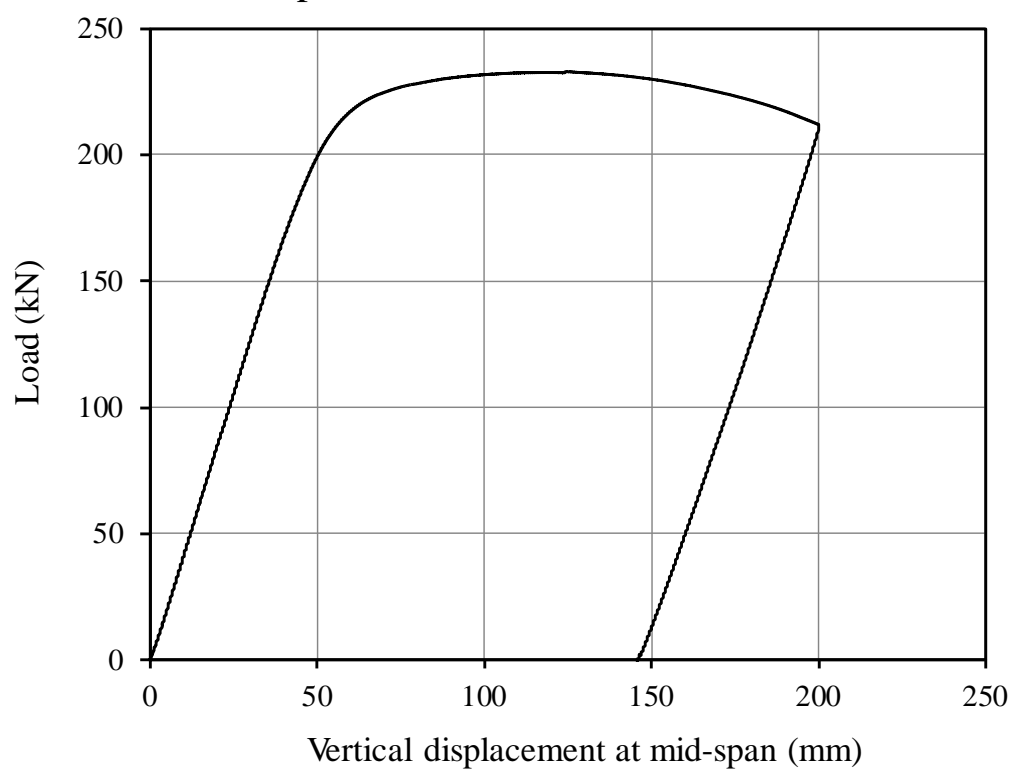

Figure 6. Load-displacement flexural response for the minor axis bending test.

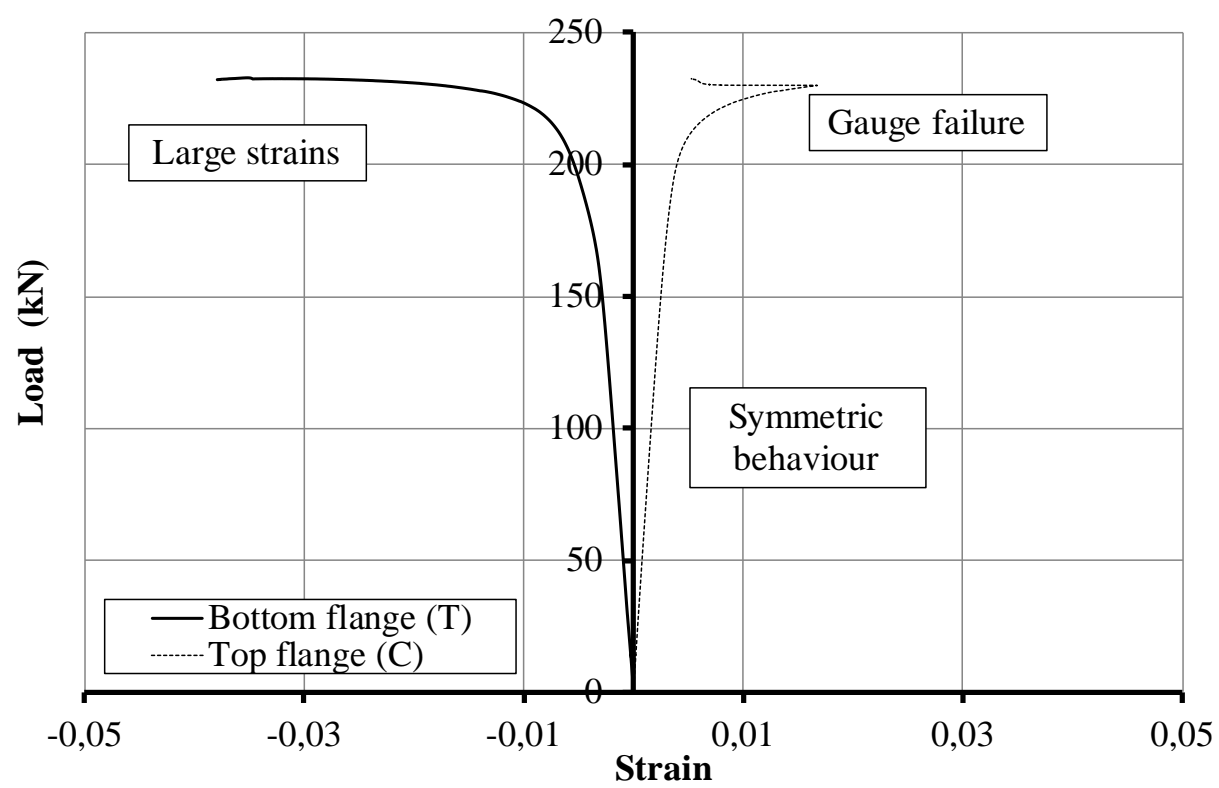

Figure 7. Load-strain curves (tensile and compressive strains) for the minor axis bending test. 


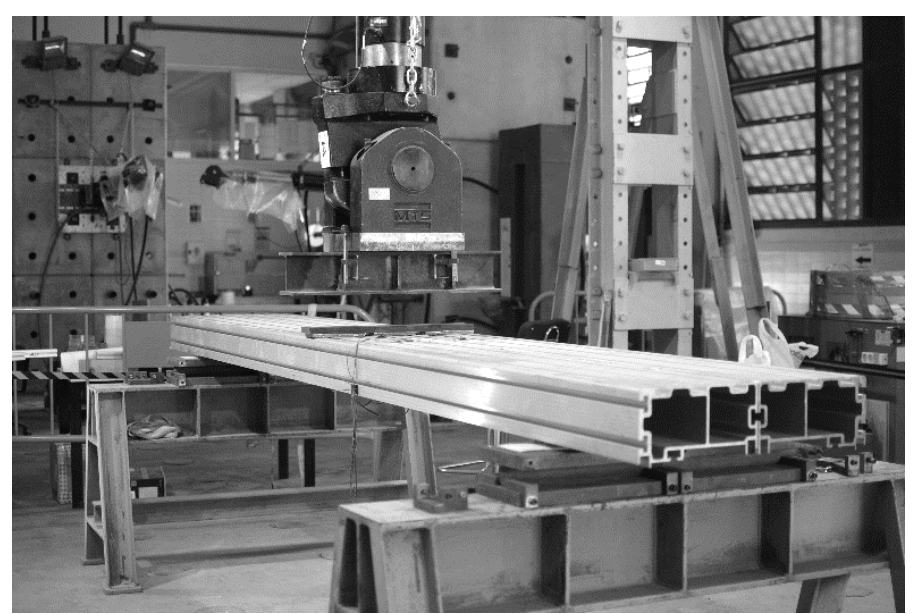

Figure 8. Minor axis bending test.

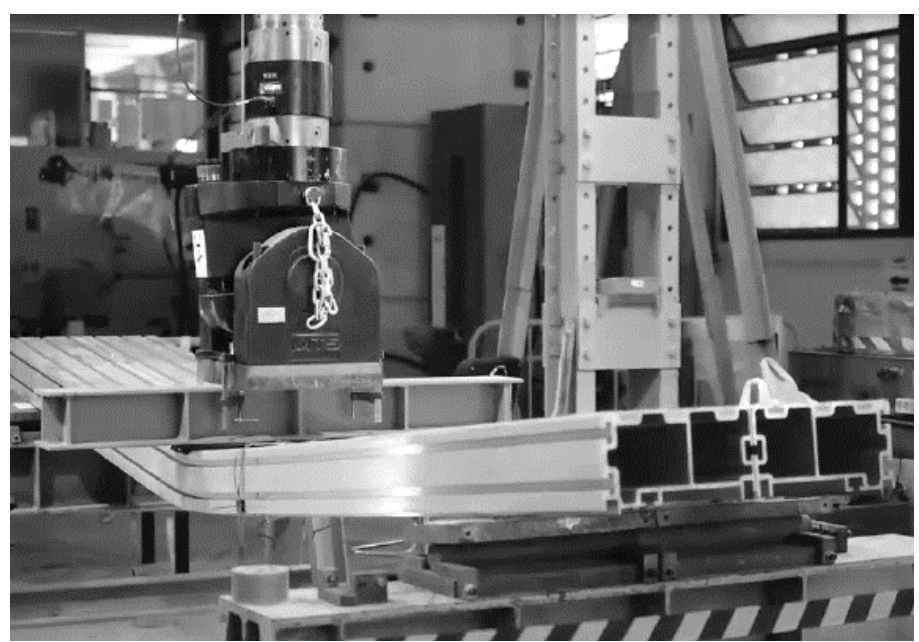

Figure 9. Observed failure mode for the minor axis bending test.

\subsection{Results for major axis bending}

A major axis bending test was performed on an aluminium girder with $3150 \mathrm{~mm}$ span. This distance was chosen due to laboratory facilities and due to the vertical stiffening of the girders, the lateral restraints (braces) and the available support hinges. Lateral braces were included to avoid an undesired lateral movement of the beam during the test. This movement is avoided in the real configuration by means of diagonal and transversal elements as well as by the ceramic floor.

A monotonically increasing load was introduced by means of two concentrated loads separated a bearing distance $\mathrm{S}_{\mathrm{s}}=150 \mathrm{~mm}$ using a MTS $1000 \mathrm{kN}$ hydraulic jack under displacement control $(0,05 \mathrm{~mm} / \mathrm{min}$ with preliminary numerical studies that showed the potential effect of a single concentrated loading, see section 4). Strain gauges were fastened on top and bottom flanges of the girder whereas the vertical deflection was similarly measured throughout the test using an LVDT at mid-span section. Fig. 10 displays the structural scheme of the test for this particular case. 


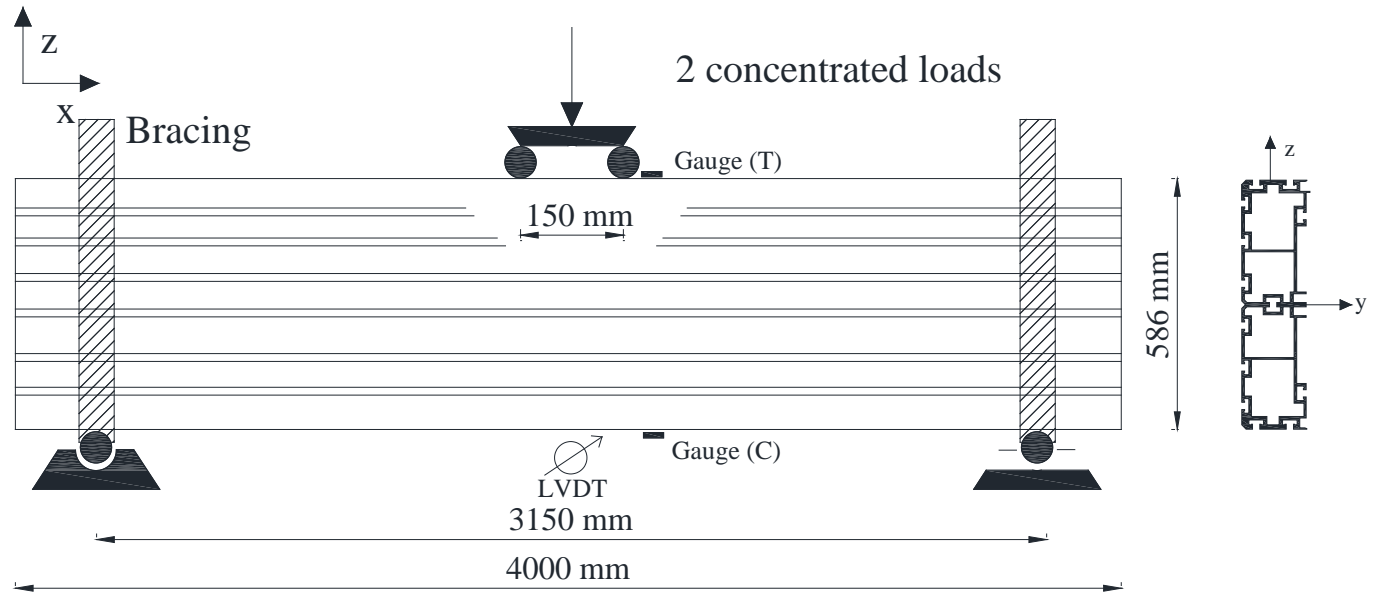

Figure 10. Lateral scheme of the major axis bending test.

The load-displacement plot is displayed in Fig. 11 whereas load-strain plots are presented in Fig. 12. For major axis bending, the observed behaviour differs from a fully flexural mode. The major axis inertia is considerably higher than the minor axis inertia so less deflection, less strain and a greater ultimate load capacity was expected. The observed load-displacement plot shows a linear branch up to the ultimate load capacity with very low deflection. However, the reached ultimate load was $299,7 \mathrm{kN}$, which is unexpectedly similar to the load obtained in minor axis bending. Further inspection of the failure mode confirmed the numerically observed mechanisms in preliminary numerical simulations. The girder failed by local concentrated loading (patch loading) and was not able to develop its full flexural capacity due to this fact. Fig. 12 shows greater strains for the gauge located on the top flange than the one located in the bottom flange, which is consistent with the observed failure mode. Fig. 13 and Fig. 14 show views of the girder before and during the test at peak load. The web folding deformation is noticeable under the applied loads.

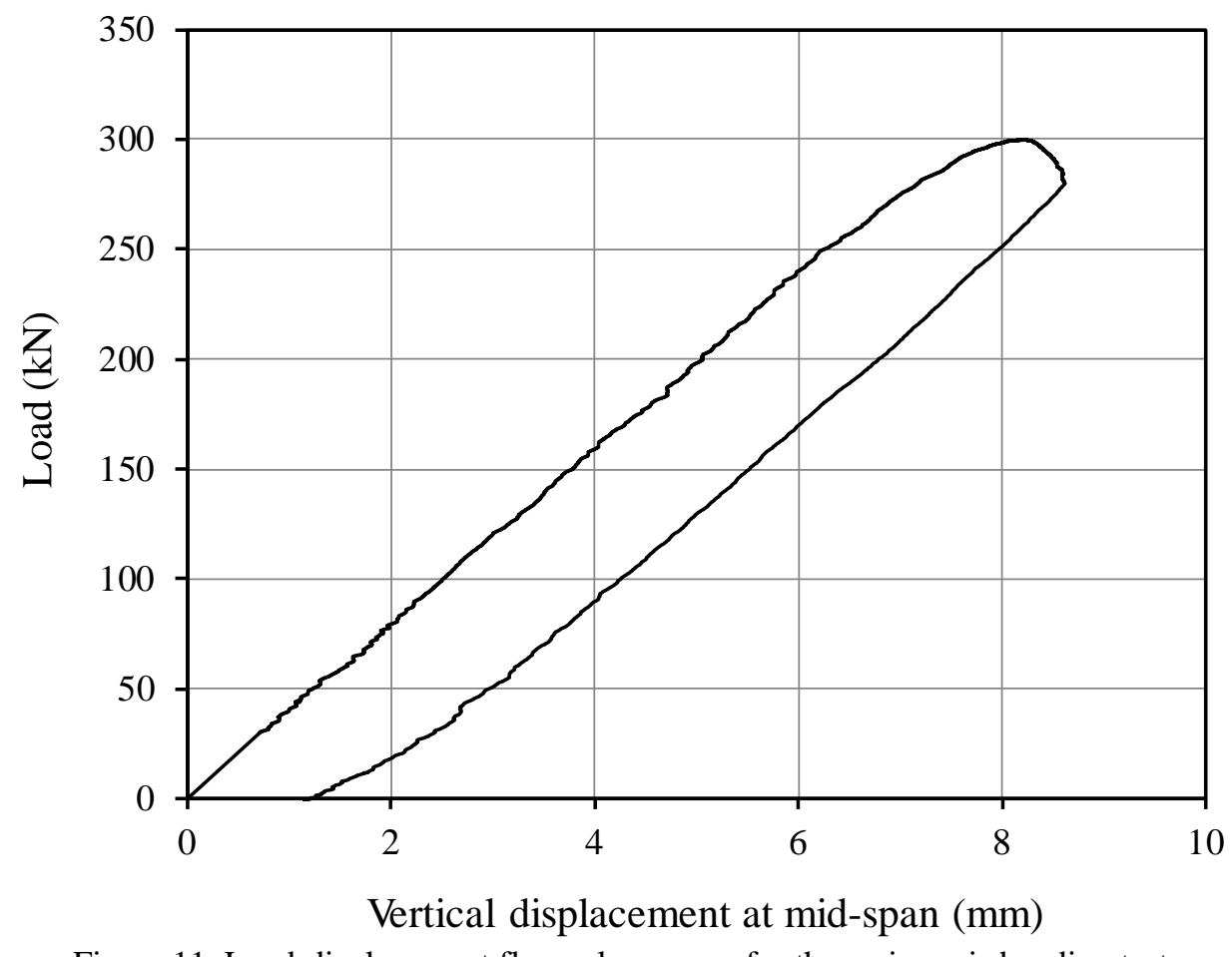

Figure 11. Load-displacement flexural response for the major axis bending test. 


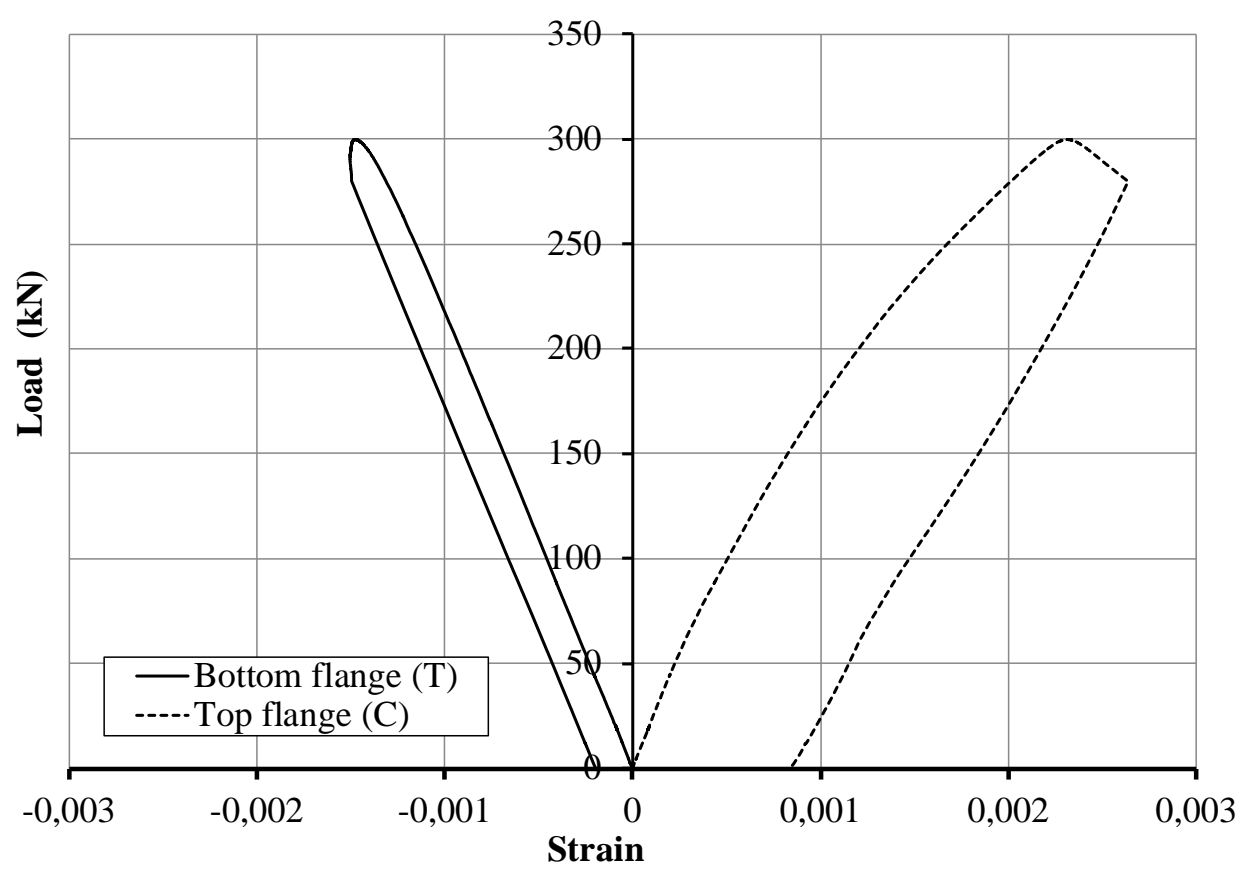

Figure 12. Load-strain response for the major axis bending test.

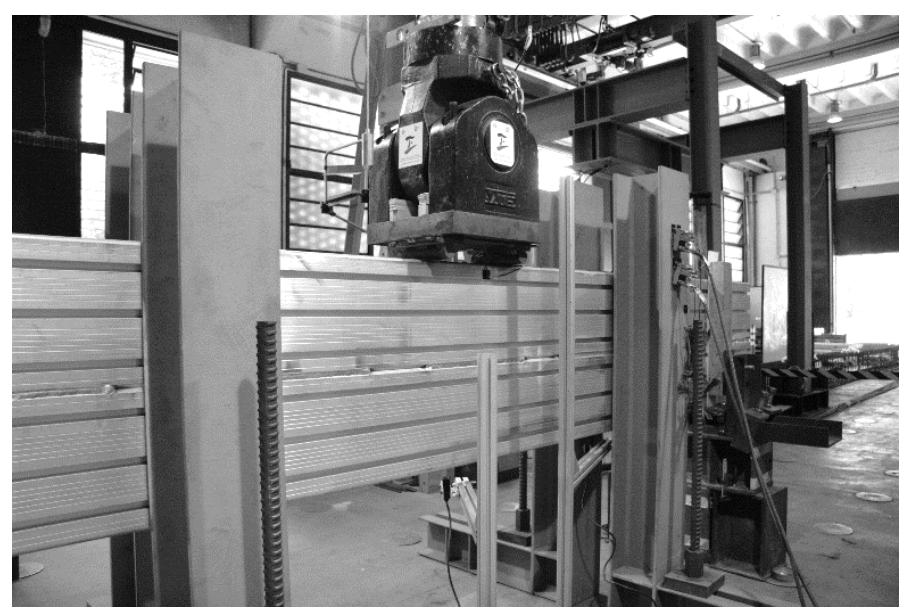

Figure 13. Major axis bending test.

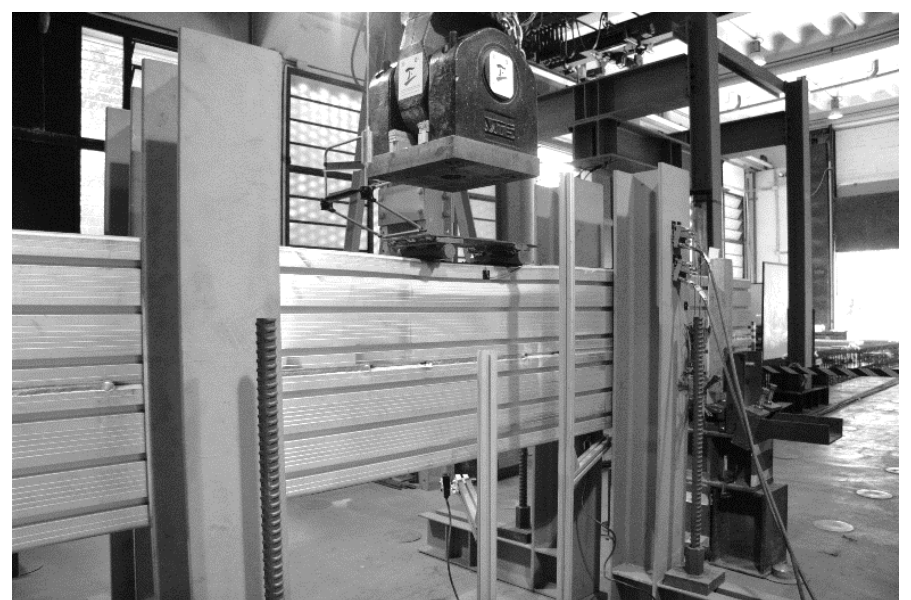

Figure 14. Observed failure mode for the major axis bending test. 


\section{Numerical analyses}

\subsection{Numerical model}

A full Geometrical and Material Nonlinear Analysis with Imperfections (GMNIA) FEbased numerical model was developed as a simulation tool. The model was implemented in the commercial Software Abaqus-Simulia [18]. The geometry of the simulated bodies was based upon shell elements with four nodes and reduced integration (S4R from Abaqus libraries). Shell elements allow developing 3D geometries realistically for cases in which one dimension is considerably smaller than the others (in this particular case, the thickness of the plates). Shell-based geometries in thin-walled structures allow developing local and/or global buckling phenomena, which are of the utmost importance in these particular simulations. It is worth bearing in mind that the plates assembling the girders must be provided with an initial imperfection for the sake of appropriately triggering its geometrical nonlinearity. In this work, the initial imperfection (out-of-plane deformed shapes of the web panels) is introduced according to the EN1993-1-5-C [19] recommendations. Previous works developed by the authors concerning the influence of initial imperfections on the numerical simulations of steel girders subjected to concentrated loads (single panels) show further insight concerning this topic [20]. The material nonlinearity for nonlinear metallic materials is based upon a Ramberg-Osgood [21] approach depicted in EN1999-1-1 Annex E [22] using $\mathrm{f}_{0}=250 \mathrm{~N} / \mathrm{mm}^{2}$ and $\varepsilon_{0, \mathrm{e}}=0,002$ (values provided by the suppliers). For multi-axial stresses, the uniaxial constitutive equation includes the von Mises criterion. Hardening is accounted for by including a linear isotropic formulation. Fig. 15 shows a view of the shell model and the resulting mesh. An advancing front automatic algorithm provided in Abaqus was set as the mesh generator. The size of the mesh was dictated by the size of the smallest plate of the crosssection. At least two quad elements were provided in such portion in order to guarantee an adequate numerical reproduction of potential local buckling of such panel.
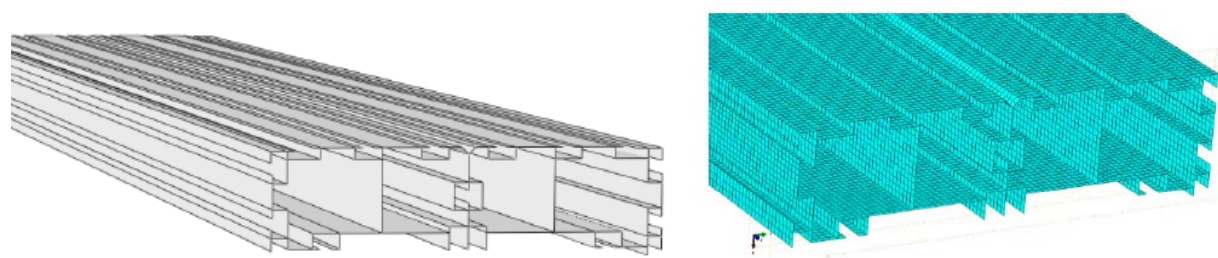

Figure 15. Shell-based model and adopted mesh.

Fig. 16 shows the adopted stress-strain relationship for the wrought aluminium (initial slope $E=71356 \mathrm{~N} / \mathrm{mm}^{2}$ ), while in Fig. 17 the loading sections and boundary conditions considered in the FE models are presented for minor and major axis bending moment test configurations. 


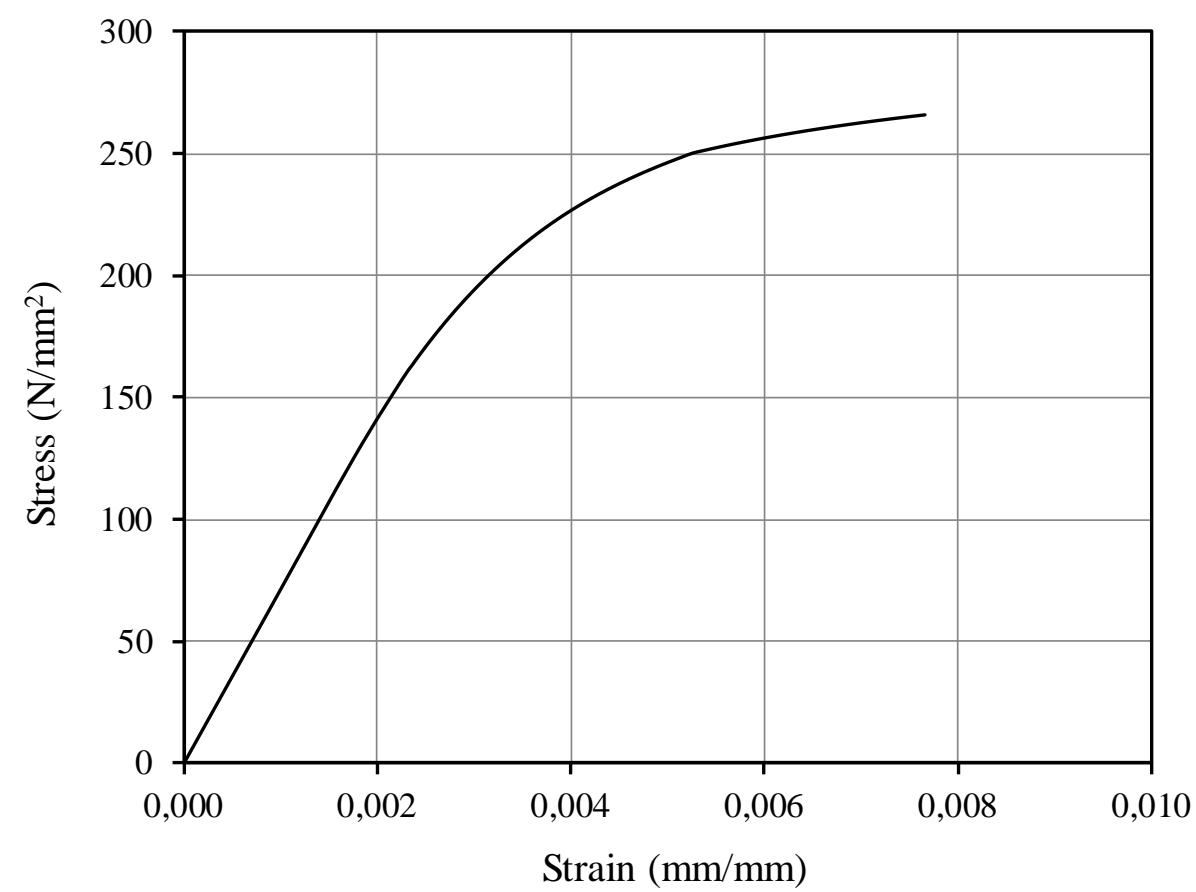

Figure 16. Numerically adopted stress-strain relationship for the wrought aluminium.
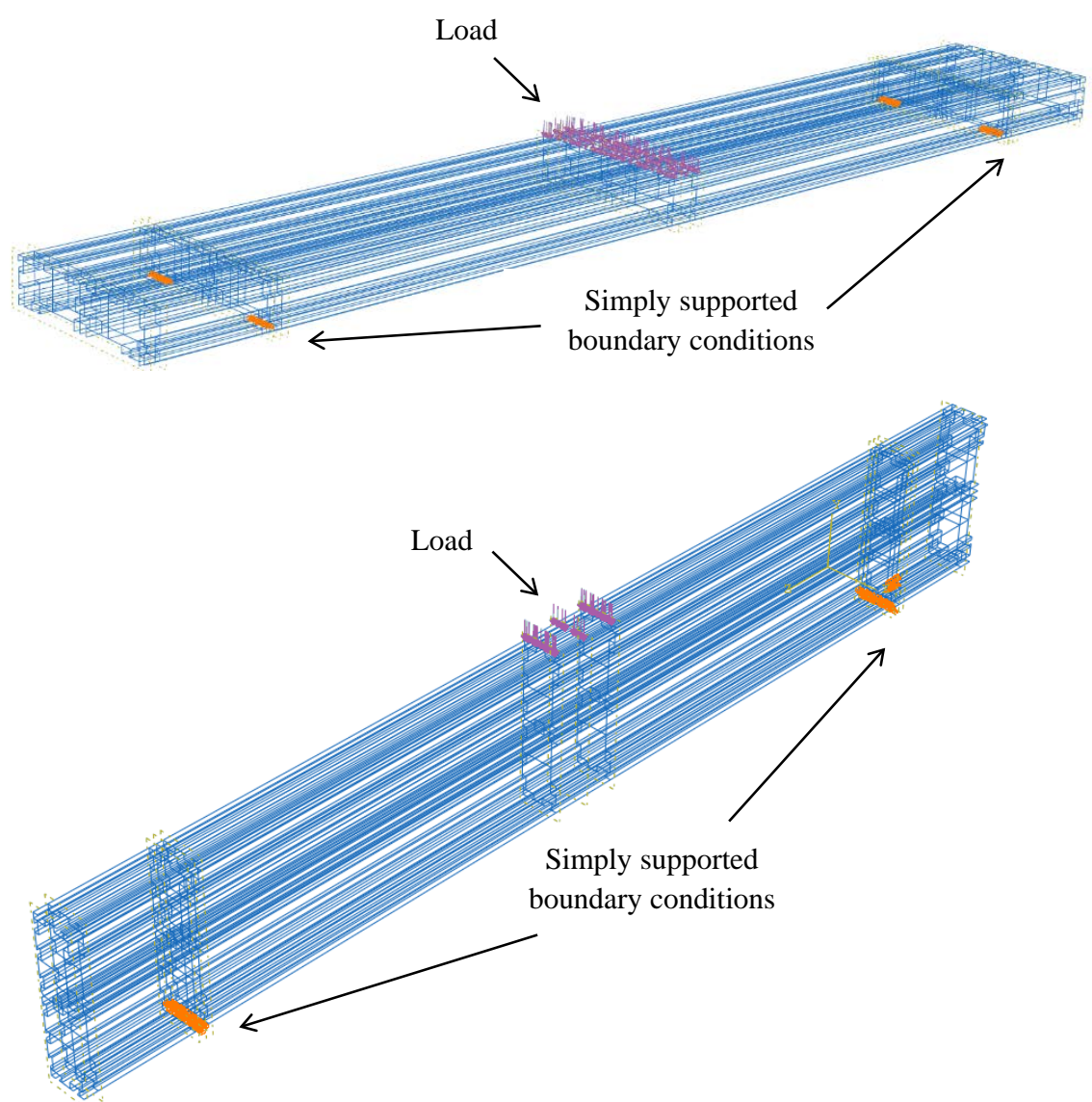

Fig. 17 Boundary conditions 


\subsection{Reproduction of the minor axis bending test}

The experimental test for minor axis presented in section 2 was numerically reproduced by adopting its geometries, material, boundary conditions and type of loading. Results are quantitatively compared in the form of load-displacement plots (Fig. 18). For minor axis bending, the observed behaviour coincides satisfactorily. Linear branches are identical and slight differences are observed at peak load. The overall curve shows that the numerical model reproduces the experimentally observed behaviour. Qualitatively, Fig. 19 shows the overall flexural deformation of the girder at peak load both experimentally and numerically.

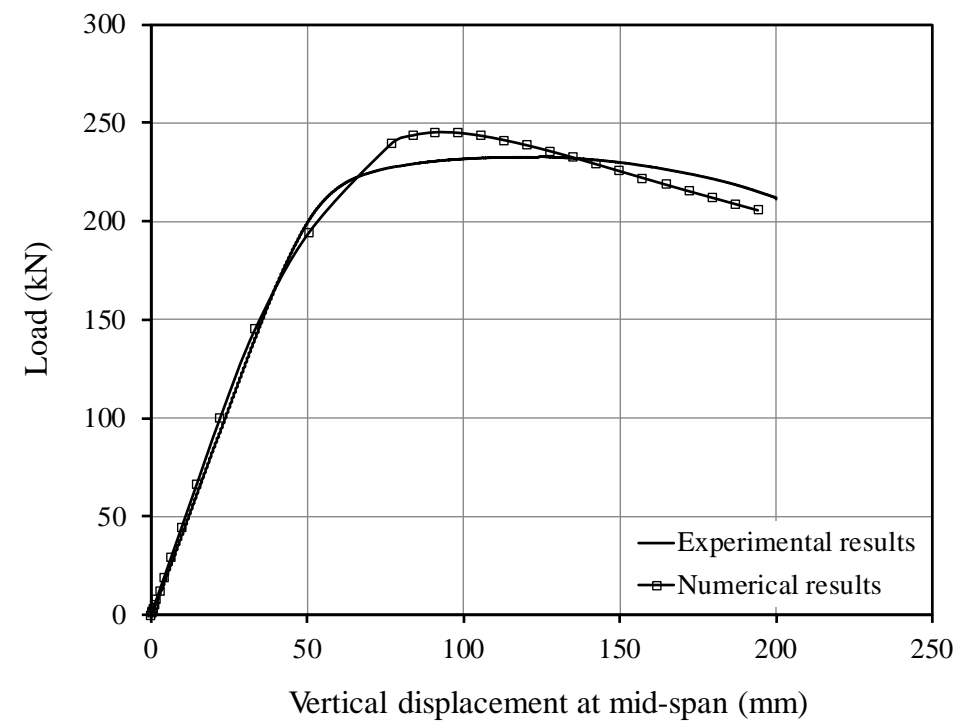

Figure 18. Experimental and numerical load-displacement flexural responses for the minor axis bending test.
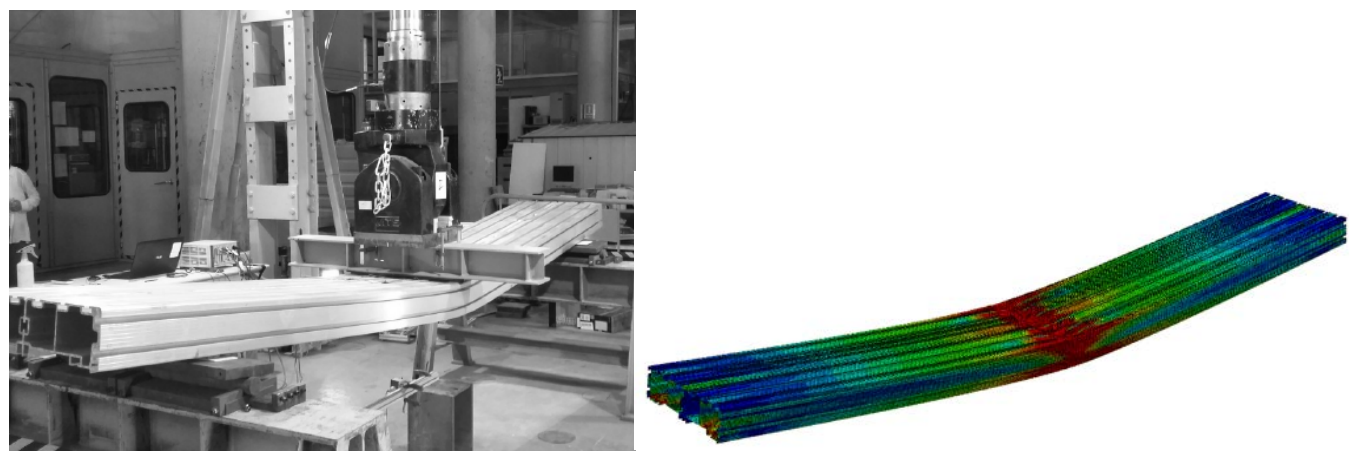

Figure 19. Experimentally and numerically observed failure modes for the minor axis bending test.

\subsection{Reproduction of the major axis bending test}

Similarly, the experimental test for major axis was numerically reproduced. Results are quantitatively compared in the form of load-displacement plots (Fig. 20). The observed behaviour also coincides satisfactorily. The overall curve shows that the numerical model reproduces the experimentally observed behaviour. Qualitatively, Fig. 21 shows the web folding deformation of the girder at peak load both experimentally and numerically. 
Noticeably, the level of displacement for this case is considerably lower than for the case of minor axis bending.

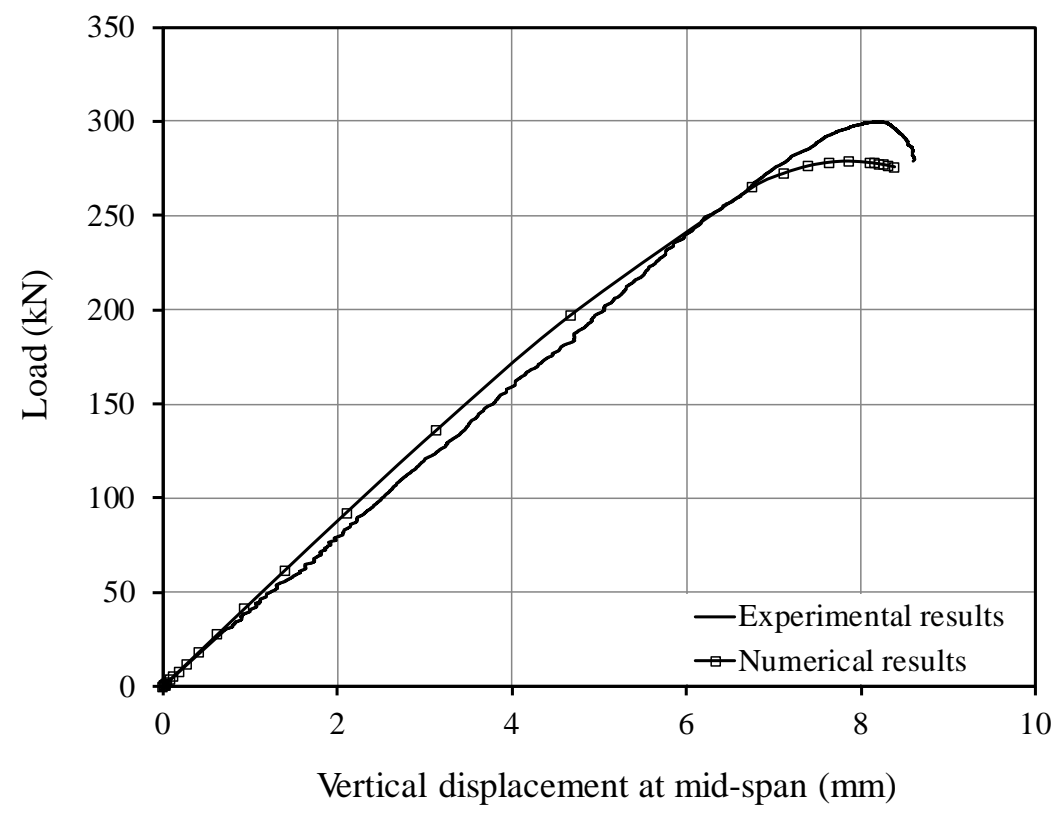

Figure 20. Experimental and numerical load-displacement flexural responses for the major axis bending test.
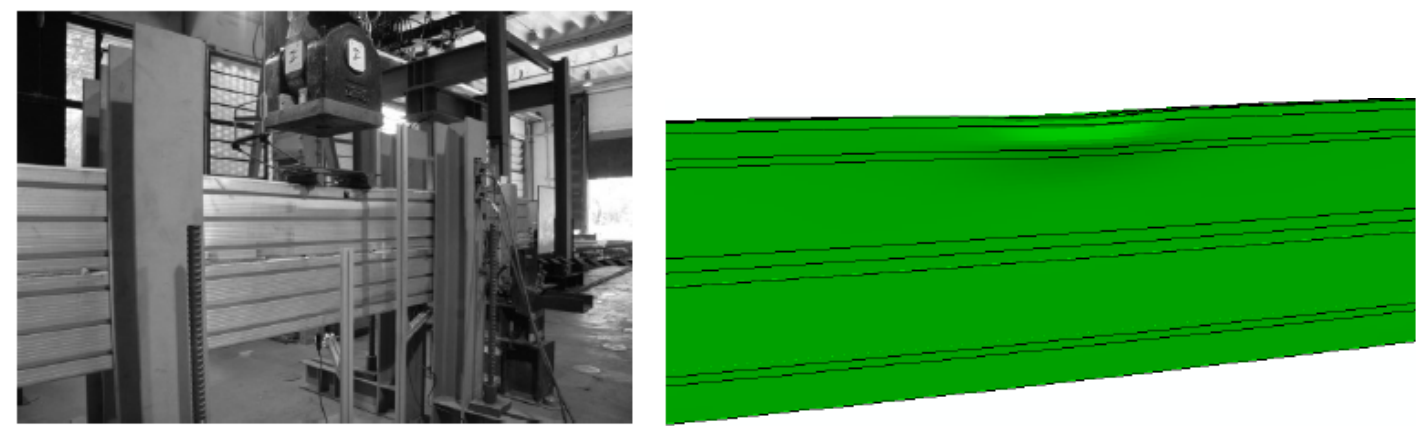

Figure 21. Experimentally and numerically observed failure modes for the major axis bending test.

\subsection{Comparison between experimental and numerical results.}

Table 1 shows the comparison between the experimental and the numerical results. Ultimate loads, displacement at peek loads and values initial stiffness are displayed. For ultimate load capacity, differences are $5 \%$ and $7 \%$ for minor and major axis, respectively. For minor axis, the numerical model provides a higher capacity and a slightly more rigid response. For major axis, the trend is inverted in terms of ultimate capacity but the values of stiffness practically coincide. Observed discrepancies are more likely to be a result of the described stress-strain relationship. 
Table 1. Experimental vs. Numerical results

\begin{tabular}{ccccc}
\hline Test & Magnitude & Experimental & Numerical & Difference \\
\hline \multirow{2}{*}{ Minor axis } & Ultimate load $(\mathrm{kN})$ & 232,8 & 245,2 & $5 \%$ \\
bending & Displacement at peak load $(\mathrm{mm})$ & 110,0 & 98,1 & $-12 \%$ \\
& Initial stiffness $(\mathrm{kN} / \mathrm{mm})$ & 4,2 & 4,5 & $7 \%$ \\
\hline \multirow{2}{*}{ Major axis } & Ultimate load $(\mathrm{kN})$ & 299,7 & 278,9 & $-7 \%$ \\
bending & Displacement at peak load $(\mathrm{mm})$ & 8,2 & 8,4 & $2 \%$ \\
& Initial stiffness $(\mathrm{kN} / \mathrm{mm})$ & 39,4 & 39,2 & $0 \%$ \\
\hline
\end{tabular}

\section{Additional numerical studies}

\subsection{Push vs. pull loads}

The asymmetric nature of the extruded cross-sections was structurally studied by varying the load application. Both cases correspond to potential lateral loads induced by crafts and equipment that generate flexural loads about minor axis. For each case, a numerical simulation of a monotonically increasing load was performed. Fig. 22 shows the loaddisplacement response for both push- and pull loads in a model with identical geometry and material of the one tested. Noticeably, the response is identical at linear branches but both peak loads differ considerably. The ultimate load capacity for push loads is $F_{u}=245,2$ $\mathrm{kN}$ whereas for pull loads is $\mathrm{F}_{\mathrm{u}}=291,6 \mathrm{kN}$ which represents a $19 \%$ relative difference.

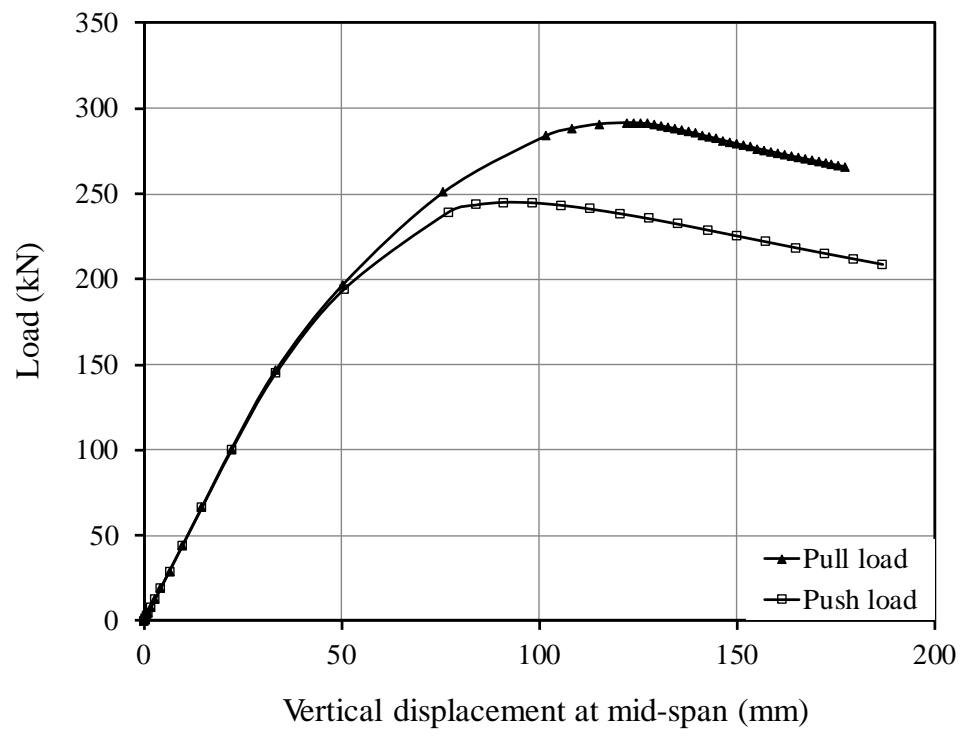

Figure 22. Push vs. pull loads. Flexural behaviour about minor axis.

\subsection{Patch vs. distributed loading}

Experimentally, it has been observed that local buckling due to concentrated loading occurs prematurely and therefore the full flexural capacity about major axis is not achieved. In the test, the load was applied at two concentrated points separated a $\mathrm{s}_{\mathrm{s}}=150$ $\mathrm{mm}$ due to laboratory facilities. In this section, a parametric study related to different load applications (bearing length $\mathrm{s}_{\mathrm{s}}$ ) is addressed. Fig. 23 shows the load-displacement responses for different types of load application in a model with identical geometry and material of the one tested. All cases correspond to push loads acting on the top flange. Pressure loads acting on a small distance $\mathrm{s}_{\mathrm{s}}=150 \mathrm{~mm}$ generate the smallest ultimate load capacity $\mathrm{F}_{\mathrm{u}}=155,1 \mathrm{kN}$ whereas a distributed load over the whole length yielded a peak 
load $\mathrm{F}_{\mathrm{u}}=490,2 \mathrm{kN}$, which represents a $316 \%$ difference. For other values of $\mathrm{s}_{\mathrm{s}}$, the obtained values of $\mathrm{F}_{\mathrm{u}}$ were consistently between both extremes. For the case of distributed loading, the failure was observed on the bearing supports in which a concentrated reaction occurs (a case which is referred to in the literature as end-patch loading). The full flexural capacity in these 5 cases was not achieved either for patch loading at mid-span or endpatch loading at supports. For all cases, it is worth noticing that the monitored displacements in Fig. 23 correspond to nodes located on the top flange (greater displacement than those obtained in bottom flanges as in the experimental test).

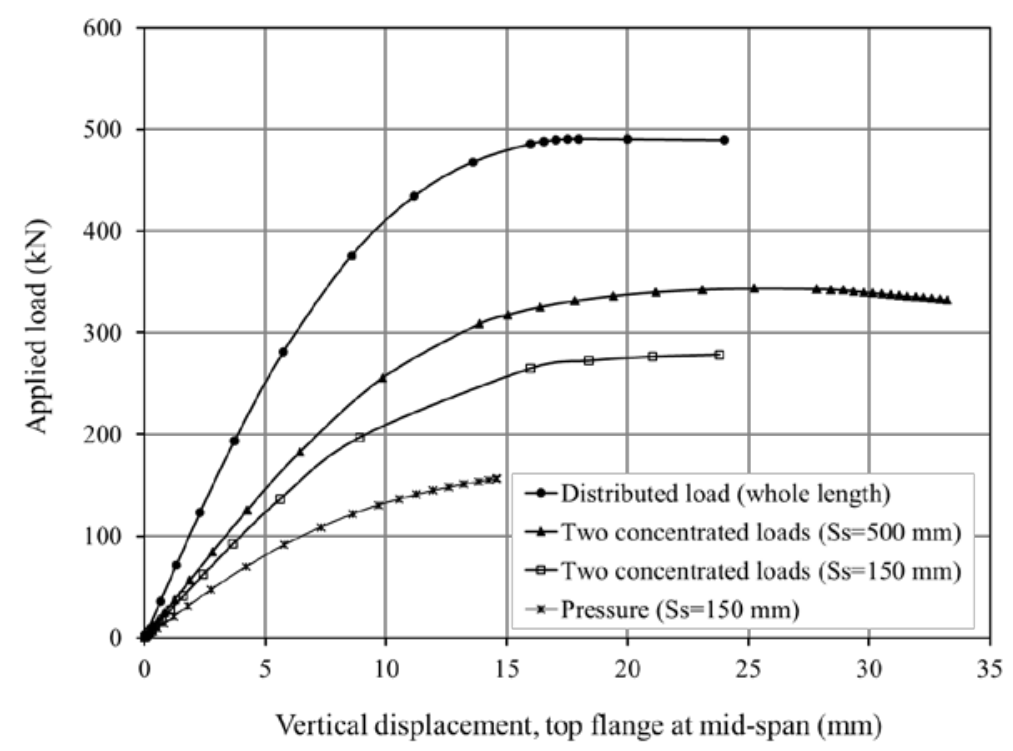

Figure 23. Patch vs. distributed loading. Flexural behaviour about major axis.

\subsection{Overall analysis of the beam}

In this section, the analysis is extended to girders with greater length belonging to a whole dock platform. A twofold set of features are worth pointing out:

- About the minor axis, a girder with a length of 10,9 m was analysed. According to the overall truss structure depicted in Fig. 1, lateral supports are found on the nodes where diagonals and horizontal RHS converge. This results in a continuous beam with four spans of $2725 \mathrm{~mm}$ each (see Fig. 24).

- About the major axis, a simply supported beam with a length of $10,9 \mathrm{~m}$ was analysed. According to the overall truss structure depicted in Fig. 1, the platform may act as a lateral restraint on the whole length but these elements do not provide vertical restraint. This results in a simply supported beam (see Fig. 27). 


\subsubsection{Minor axis}

A structural analysis of the model described in Fig. 24 was performed with identical characteristics than other models. The results showed a continuous beam with high rotation capacity in which hinges are formed in both hogging and sagging zones. A fully plastic mechanism is observed in Fig. 25 in which AB span is displayed (other spans showed similar behaviour). Fig. 26 displays the evolution of reactions at supports for the monotonically increasing loading process. Local instabilities only occur at considerable values of displacement corresponding to load levels clearly higher than the design loads.

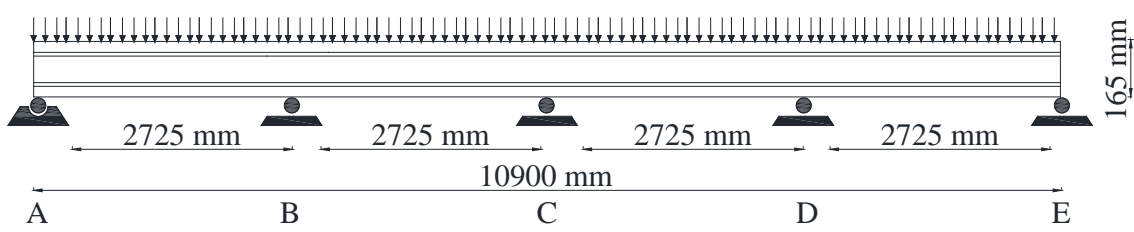

Figure 24. Model of a continuous beam loaded about its minor axis.

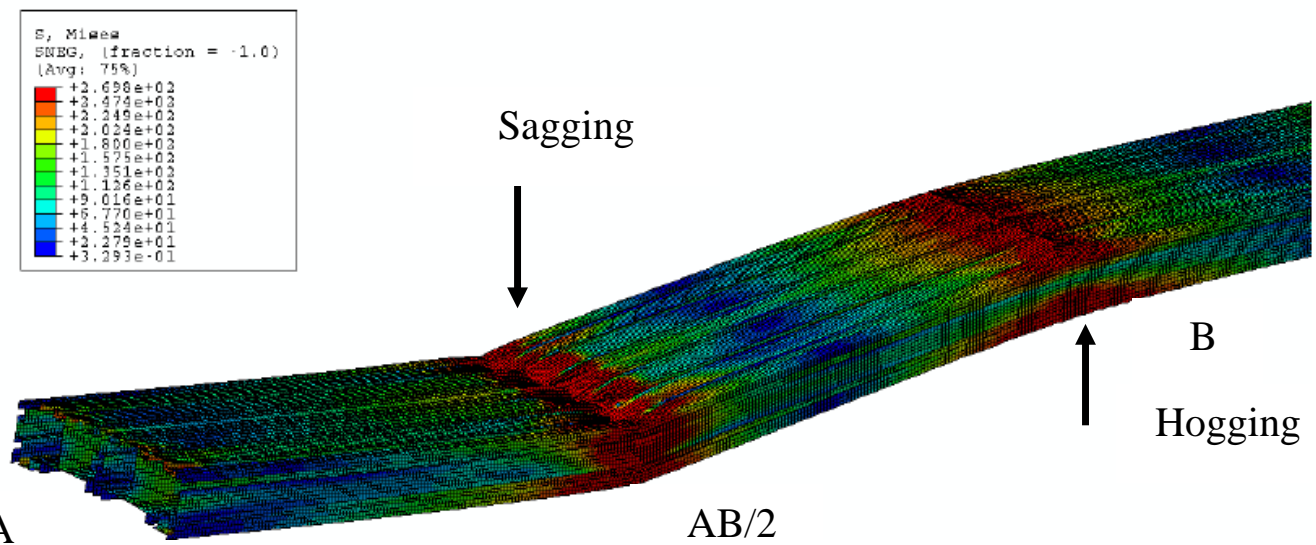

Figure 25. Hogging and sagging zones observed in a continuous beam loaded about its minor axis.

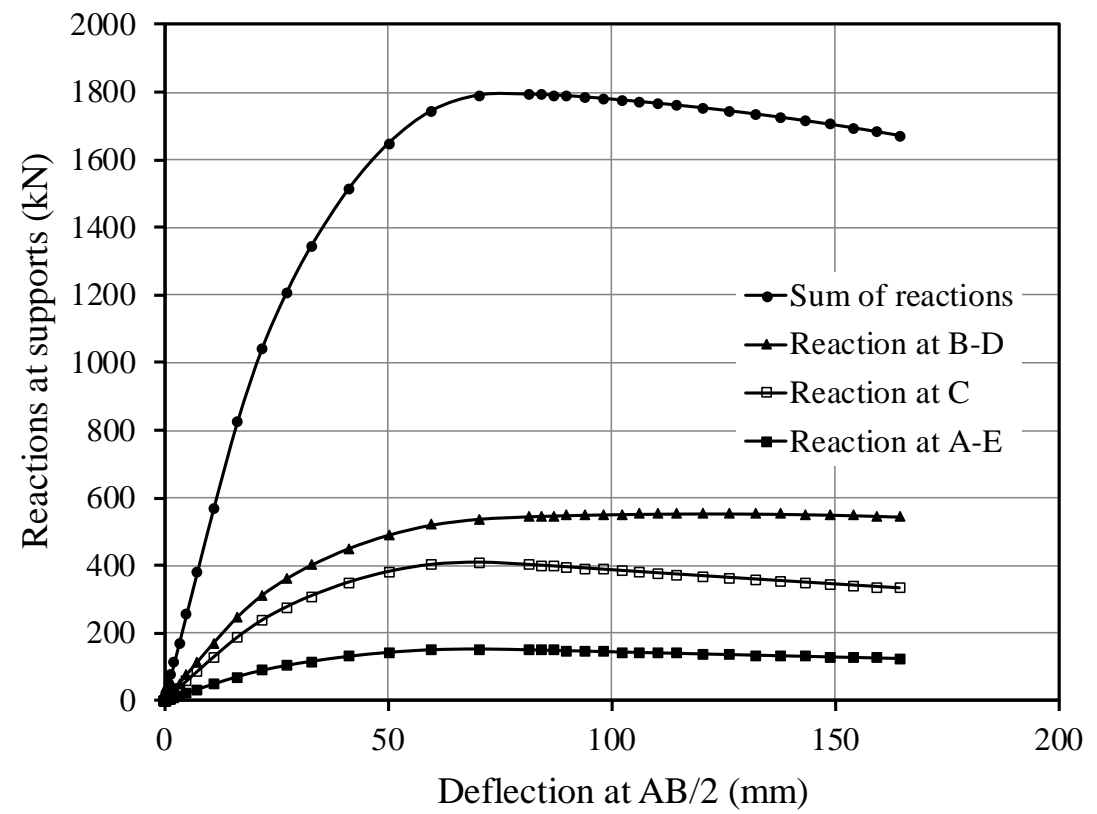

Figure 26. Calculated reactions for the continuous beam loaded about its minor axis. 


\subsubsection{Major axis}

A structural analysis of the model depicted in Fig. 27 was performed with identical characteristics than previous models. The model was conservatively assumed as simply-supported with the totality of the load applied on the top and an unbraced length similar to the real situation. In this particular case, the results showed a simply supported beam unable to develop a full flexural capacity due to concentrated loading at the supports. The lack of vertical stiffeners at supports penalises considerably the overall flexural behaviour. Fig. 28 displays a lateral zoomed view in the vicinity of the supports which show a clear local deformation due to concentrated loading. Finally, Fig. 29 shows a reaction-displacement response curve. It is observed that the maximum load is lower than the reaction obtained in other models presented in Fig. 23. The difference between the maximum reaction obtained in this case and the maximum reaction obtained for other cases is partly attributed to the length of this element, but most importantly, to the relationship between the total length of the element and the length from the unstiffened support to the physical end of the element. End-patch loading is a more severe type of loading than regular patch loading. For the particular case of extruded elements without stiffening at supports, this phenomenon undermines the flexural capacity. In any case, it is interesting to note that the sum of all resistances to end-patch loading (two girders, to supports) is equivalent to a surface load of approximately, $25 \mathrm{kN} / \mathrm{m}^{2}$, a value which is higher than the design load in this type of structures.

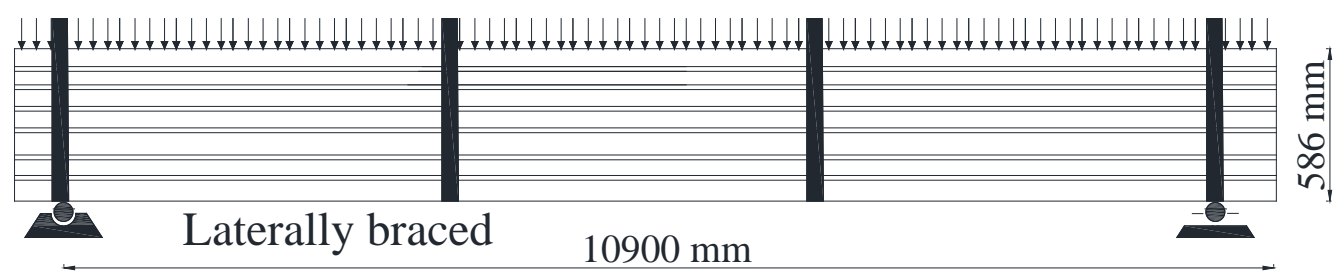

Figure 27. Model of a simply supported laterally braced beam loaded about major axis.

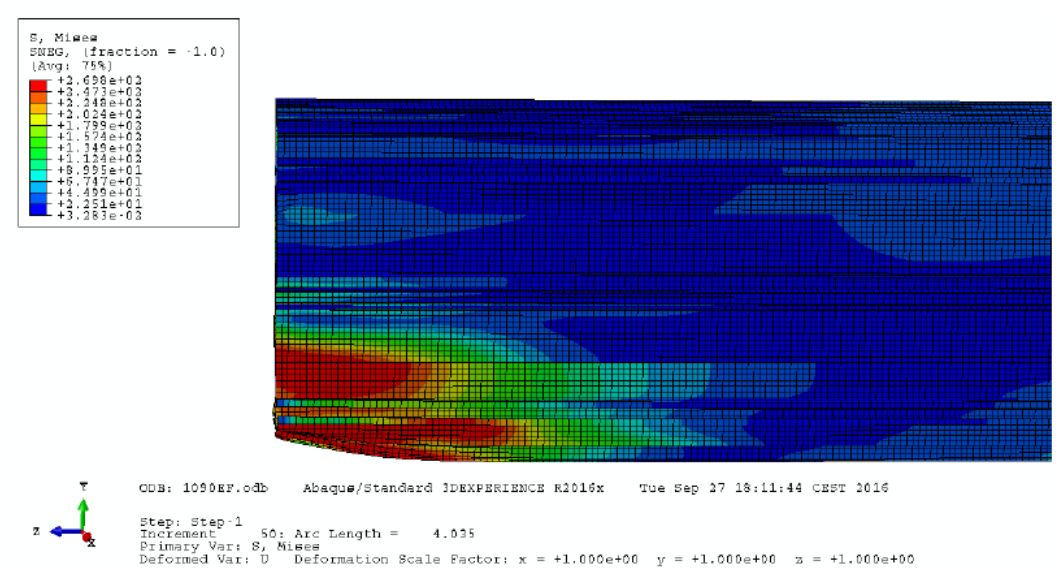

Figure 28. End-patch loading mechanism in a simply supported beam loaded about its major axis. 


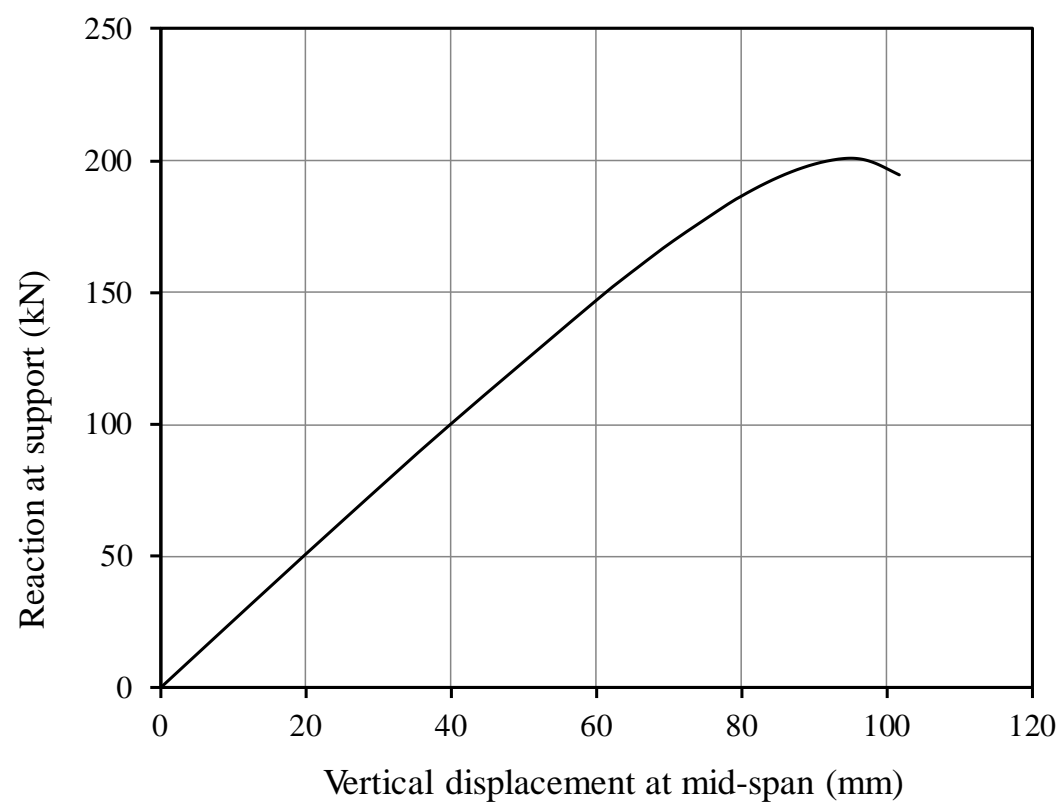

Figure 29. Reaction evolution for the simply supported beam loaded about its major axis.

\section{Results and discussion}

In this paper, the flexural response of an extruded wrought aluminium girder is presented. The focus of the study is the usage of such elements as the main resistant member of light dock platforms intended for small marinas and yacht ports. The main advantage of the studied girders is the extrusion process, which may generate bespoke cross-sections that fulfil both structural and operational needs such as fixations of mooring lines, facilitation of construction processes or similar non-structural properties. The analysed cross-sections are non-symmetric for minor axis and symmetric for the major axis.

Experimental tests related to the flexural behaviour of the elements are presented. A satisfactory numerical reproduction that validates a subsequent systematic analysis of the structure is included in the study. As a result, several conclusions related to the flexural response of the girders are pointed out:

- About its minor axis, which resists potential lateral loads generated by the crafts, the flexural behaviour showed elements with a considerably high rotation capacity and with non-symmetric behaviour for both push and pull loads. In all the studied cases (simply supported or continuous configuration) the element proved compact with high rotation capacity.

- About its major axis, which resists potential gravity loads generated by the operation on the platform, the flexural behaviour showed elements with a considerably low rotation capacity due to a localised failure in the vicinity of the load application area. In all the studied cases local patch- or end-patch loading were obtained.

- From the design perspective, it is worth pointing out that the extrusion process facilitates the production of bespoke cross-section longitudinally. Transversally, however, vertical stiffeners are often needed for the sake of avoiding localised 
vertical deformation due to patch or -end patch loads. Vertical ribs are necessary if a full development of flexural capacity is needed. In any case, the values of total surface load that may be achieved by adding the resistance of four supports is considerably higher than the design load in this type of structures.

\section{Acknowledgements}

The authors acknowledge the collaboration of the Port de Mataró local authorities as to Cedipsa and Astilleros Amilibia for providing the corresponding material for the tests.

\section{References}

[1] Dumont C., Hill H.N., Lateral Stability of equal flanged aluminium alloy I-beams subjected to pure bending. NACA TN 770. 1940

[2] De Matteris G., Moen L.A., Langseth M., Landolfo R., Hopperstad O.S., Mazzolani F.M. Cross-sectional classification for aluminium beams: a parametric study. Journal of Structural Engineering, ASCE. Vol. 127(3), pp. 271-279. 2001

[3] Moen L.A., Hopperstad O.S., Langseth M. Rotational capacity of aluminium beams under moment gradient I: experiments. Journal of Structural Engineering. ASCE. Vol. 125 (8). pp. 91020. 1999

[4] Moen L.A., De Matteis G., Hopperstad O.S., Langseth M., Landolfo R., Mazzolani F.M., Rotational capacity of aluminium beams under moment gradient II: numerical simulations. Journal of Structural Engineering. ASCE. Vol. 125 (8). pp. 921-929. 1999

[5] Yuan H.X., Wang Y.Q., Chang T., Du X.X., Bu Y.D., Shi Y.J. Local buckling and postbuckling strength of extruded aluminium alloy stub columns with slender I-beams. Thin-Walled Structures. Vol. 90, pp. 140-149. 2015

[6] Wang Y.Q., Wang Z.X., Yin F.X., Yang L., Shi Y.J., Yin J. Experimental study and finite element analysis on the local buckling behavior of aluminium alloy beams under concentrated loads. Thin-Walled Structures. Vol. 105, pp. 44-56. 2016

[7] Wang Y.Q., Yuan H.X., Shi Y.J., Cheng M. Lateral-Torsional buckling resistance of aluminium I-beams. Thin-Walled Structures. Vol. 50(1), pp. 24-36. 2012

[8] Su M.N., Young B., Gardner L. Deformation-based design of aluminium alloy beams. Engineering Structures. Vol. 80, pp. 339-349. 2014

[9] Kim Y., Peköz P. Ultimate flexural strength of aluminium sections. Thin-Walled Structures. Vol. 48(10-11), pp. 857-865. 2010

[10] Su MN., Young B., Gardner L. Flexural response of aluminium alloy SHS and RHS with internal stiffeners. Engineering Structures. Vol. 121, pp. 170-180. 2016

[11] Wehrle R., Baier H. Establishing manufacturing effort models to be used in optimization of extruded aluminium profiles under structural and manufacturing criteria. Procedia CIRP 18, pp. 150-155. 2014

[12] Tercelj M., Fazarinc M., Kugler G., Perus I. Influence of the chemical composition and process parameters on the mechanical properties of an extruded aluminium alloy for highly loaded structural parts. Construction and Building Materials. Vol. 44, pp. 781-791. 2013 
[13] Stacey M., Bayliss C. Aluminium and durability: Reviewed by inspection and testing. MaterialsToday: Proceedings. Vol. 2(10-A), pp. 5088-5095. 2015

[14] Sun S., Zheng Q., Li D., Hu S., Wen J. Exfoliation corrosion of extruded 2024-T4 in the coastal environments in China. Corrosion Science. Vol. 53 (8), pp. 2527-2538. 2011.

[15] Reza Khedmati M., Bayatfar A., Rigo P. Post-buckling behaviour and strength of multistiffened aluminium panels under combined axial compression and lateral pressure. Marine Structures. Vol. 23 (1), pp. 39-66. 2010

[16] Rigo P., Sarghiuta R., Estefen S., Lehmann E., Otelea S.C., Pasqualino I., Simonsen B.C., Wan Z., Yao T. Sensitivity analysis on ultimate strength of aluminium stiffened panels. Marine Structures. Vol.16 (6), pp. 437-468. 2003

[17] Latorre R.G., Herrignton P.D., Mattei N.J. Stress analysis of a transversely loaded aluminum weldment. Marine Structures. Vol. 15 (2), pp. 175-191. 2002.

[18] Abaqus FEA, Simulia@ V6.10.3. Dassault Systèmes. 2013.

[19] EN1993-1-5. Eurocode 3. Design of steel structures - Part 1-5: Plated structural elements CEN. 2006

[20] Chacón R., Mirambell E., Real E. Influence of designer-assumed initial conditions on the numerical modeling of steel plate girders subjected to patch loading. Thin-Walled Structures. Vol. 47 (4). pp. 391-402. 2009.

[21] Ramberg W., Osgood W.R., Description of stress-strain curves by three parameters, in: Technical Note No. 902, National Advisory Committee for Aeronautics, Washington, DC, 1943

[22] EN1999-1-1. Eurocode 9. Design of aluminium structures - Part 1-1: General structural rules. CEN. 2006

[23] Courtesy of the manufacturers. Cedipsa Amilibia. 2016 